\title{
Going viral: doctors must tackle fake news in the covid-19 pandemic
}

\author{
Cathal O'Connor dermatology specialist registrar ${ }^{12}$, Michelle Murphy consultant dermatologist ${ }^{12}$ \\ 'Department of Dermatology, South Infirmary Victoria University Hospital, Cork T12 X23H, Republic of Ireland; ${ }^{2}$ University College Cork
}

"Dúirt bean liom go ndúirt bean léi-a woman told me that a woman told her"-Irish proverb.

The general public has been overwhelmed with information related to the novel coronavirus. ${ }^{1}$ In Ireland the medical community has noted a trend of messages containing incorrect information about covid-19 spreading rapidly through social media and messaging apps. Misinformation is defined as false information that is communicated without deliberate malice; disinformation is false information that is communicated with the intent to deceive. ${ }^{2}$ The motivation behind creating these messages is unclear but might relate to attention seeking behaviour and conspiracist ideation. ${ }^{34}$

The false messages that we have seen tend to contain common features. They claim to have inside information from, for example, a young researcher from Wuhan, a Taiwanese expert, or Dr Tim in Cork, but no reference is provided to support the alleged source. The tone is often alarmist, implying that if the suggested action is ignored, serious consequences will occur- "Please do this before it's too late." The message is intended to trigger panic and fear in the reader. This increases the likelihood that the message will be shared with family and friends.

False messages are predominantly compromised of text, but some images have been shared, with text describing information that is factually discordant with the image. Voice notes have also been used to share false information, with local accents to increase credibility. Medical misinformation has centred around key themes: food and beverages as "cures," hygiene practices, and medicines.

We have seen the implications of these fake messages in clinical practice in Cork. Some patients have been unwilling to take ibuprofen, leaving non-covid illnesses untreated. Other patients with serious, time sensitive non-covid illnesses—-such as stroke-have had delayed presentations, with irreversible deficits because of concerns about contracting covid-19 in hospital. ${ }^{5}$ False information in messages has detracted from the evidence based precautions that the health service is promoting, such as social distancing and hand hygiene.

The World Health Organization has confronted fake news by offering a WhatsApp service (+41798931892) for updates. Evidence shows that healthcare professionals can stop the spread of false information by refuting or rebutting misleading health information on social media and by providing appropriate sources to accompany their refutation. ${ }^{67}$ We exhort our international colleagues to support each other in tackling fake information as they contend with covid-19.

\section{Competing interests: None declared.}

Full response at: https://www.bmj.com/content/368/bmj.m1090/rr-10.

1 Tanne JH, Hayasaki E, Zastrow M, Pulla P, Smith P, Rada AG. Covid-19: how doctors and healthcare systems are tackling coronavirus worldwide. BMJ 2020;368:m1090. 10.1136/bmj.m1090 32188598

2 Unesco. Journalism, "fake news" and disinformation: a handbook for journalism education and training. 2018. https://en.unesco.org/fightfakenews

3 Wang Y, McKee M, Torbica A, Stuckler D. Systematic literature review on the spread of health-related misinformation on social media. Soc Sci Med 2019;240:112552. 10.1016/.socscimed.2019.112552. 31561111

4 Weigmann $\mathrm{K}$. The genesis of a conspiracy theory: Why do people believe in scientific conspiracy theories and how do they spread?EMBO Rep 2018;19:e45935. 10.15252/embr.201845935. 29491005

5 Ronan Collins. Twitter. 16 Mar 2020. https://twitter.com/ronancollins7/status/ 1239507193940058113

6 Chou WS, Oh A, Klein WMP. Addressing health-related misinformation on social media. JAMA 2018;320:2417-8. 10.1001/jama.2018.16865. 30428002

7 Bode L, Vraga EK. See something, say something: correction of global health misinformation on social media. Health Commun 2018;33:1131-40. 10.1080/10410236.2017.1331312. 28622038

Published by the BMJ Publishing Group Limited. For permission to use (where not already granted under a licence) please go to http://group.bmj.com/group/rights-licensing/ permissions 